\title{
Smart Fishery: A Systematic Review and Research Agenda for Sustainable Fisheries in the Age of AI
}

\author{
Sanaz Honarmand Ebrahimi *(D), Marinus Ossewaarde (D) and Ariana Need
}

Citation: Honarmand Ebrahimi, S.; Ossewaarde, M.; Need, A. Smart Fishery: A Systematic Review and Research Agenda for Sustainable Fisheries in the Age of AI. Sustainability 2021, 13, 6037. https:// doi.org/10.3390/su13116037

Academic Editors: Jean-Claude Thill and Prabhakar Kudva

Received: 29 April 2021

Accepted: 22 May 2021

Published: 27 May 2021

Publisher's Note: MDPI stays neutral with regard to jurisdictional claims in published maps and institutional affiliations.

Copyright: (c) 2021 by the authors. Licensee MDPI, Basel, Switzerland. This article is an open access article distributed under the terms and conditions of the Creative Commons Attribution (CC BY) license (https:// creativecommons.org/licenses/by/ $4.0 /)$.
Department of Public Administration, Faculty of Behavioural, Management and Social Sciences (BMS), University of Twente, Drienerlolaan 5, 7522 NB Enschede, The Netherlands; m.r.r.ossewaarde@utwente.nl (M.O.); a.need@utwente.nl (A.N.)

* Correspondence: s.honarmandebrahimi@utwente.nl

Abstract: Applications of artificial intelligence (AI) technologies for improving the sustainability of the smart fishery have become widespread. While sustainability is often claimed to be the desired outcome of AI applications, there is as yet little evidence on how AI contributes to the sustainable fishery. The purpose of this paper is to perform a systematic review of the literature on the smart fishery and to identify upcoming themes for future research on the sustainable fishery in the Age of AI. The findings of the review reveal that scholarly attention in AI-inspired fishery literature focuses mostly on automation of fishery resources monitoring, mainly detection, identification, and classification. Some papers list marine health and primary production which are vital dimensions for Large Marine Ecosystems to recycle nutrients to sustain anticipated production levels. Very few reviewed articles refer to assessing individual needs, particularly fishers, from AI deployment in fisheries and policy response from governments. We call for future AI for sustainable fishery studies on how fishers perceive AI needs, and how governments possess a tangible strategy or depth of understanding on the regulation of AI concerning smart fishery systems and research on resilience-enhancing policies to promote the value and potentials of the AI-inspired smart fishery in different locations.

Keywords: artificial intelligence (AI); automation; fishery systems; smart fishery; sustainable fishery

\section{Introduction}

A wide variety of stakeholders point to the application of artificial intelligence technologies in the smart fishery [1-3] to solve the problem of shrinking fish stock [4]. The United Nations, the European Union, and national governments have since 2018 drafted their AI strategies, in which a so-called new 'age of AI' was announced [5]. On a global governance level, the UN has its AI for Good series since 2017. This platform was established for evaluating opportunities offered by AI for advancing the UN's Sustainable Development Goals (SDGs) and to ensure that AI benefits all humanity. The UN's AI for Good series rests on the belief that $\mathrm{AI}$ is a benevolent force that will solve the most tenacious problems of humanity, including environmental degradation of marine ecosystems and the shrinking of fish stock. Similar beliefs are expressed in the EU's AI Strategy and national AI strategies. In such concerted politics of AI, AI is presented as the benign force that, amongst other things, solves ecosystem problems [6].

The smart fishery literature of the past decade has made great headway in increasing our understanding of the workings of AI technologies in fish farming, particularly focusing on specific aspects of optimizing the efficient use of resources in ecosystem management [2,6]. In this paper we perform a systematic literature review to reconstruct the state-of-the art of the smart fishery literature, with the deliberate aim of finding out in what ways AI is embedded in the scientific field of sustainable fishery. We seek to systematically draw together AI for sustainability with different aspects of marine fishery systems in a cross-disciplinary and coherent way, to find out what is known and what is yet to be 
found out about marine smart fishery. Our systematic review serves as a foundation for identifying future research themes for the upcoming decade.

This paper is organized as follows: Section 2 presents the materials and method followed for the systematic review, Section 3 details the results, Section 4 analyzes the reviewed papers, Section 5 presents the research agenda, and Section 6 concludes the paper.

\section{Materials and Methods}

In this paper, the Preferred Reporting Items for Systematic Reviews and Meta-analyses (PRISMA) methodology is used for performing a systematic review [7-9]. The PRISMA Statement is a road map to help authors best describe what was done, what was found, and in the case of a review protocol, what are they planning to do [10]. We adopt a threephase methodologic approach. (Stage 1) Planning stage contains objectives and review protocol for a systematic review, defining sources and procedures for literature searchers. (Stage 2) Conducting the review stage contains descriptive and structural analysis. (Stage 3) Reporting and dissemination stage contains analysis and synthesis of the results according to the established objectives.

In Stage 1 (planning stage), a research plan involving the research aim and question, keywords and a set of primary inclusion and exclusion criteria of articles are developed. The search, which we conducted in December 2020, utilizes Scopus as an electronically accessible and widely used database. The choice of this database takes into consideration its scope and relevance in academia. This database indexes several journals and catalogues, such as IEEE, ACM, and Elsevier. It is a database that is widely used in similar bibliographic reviews $[8,11]$. Our goal is to systematically summarize a corpus of research papers that are directly (see search string A) and indirectly (see search strings B, C, and D) related to fishery systems (sea) using scientific searching criteria. We refer to sea as relatively large areas of oceans space $\left(\geq 200,000 \mathrm{~km}^{2}\right)$ called Large Marine Ecosystems (LMEs) [12]. The query strings $B$ and $C$ present the marine ecosystem health and primary production modules of the LMEs approach. We added "marine ecosystem" in a separate query to search for all related topics in all five modules of LMEs approach.

Since the mid-1980s, the LMEs approach combines multiple disciplines (fish/fishery, ecosystem health, primary production, governance, and socioeconomics) for implementing natural science and social science-based assessment of coastal goods and services [12]. Like smart fishery, its ultimate goal is moving towards sustainable development of fishery through a combination of science, policy, and society [12]. We use this approach in identifying upcoming themes for future research on sustainable fishery in the Age of AI.

Search string A: "Artificial intelligence" OR ai OR smart) AND (fish) AND (fishery) AND (system) Search string B: ("Artificial intelligence" OR "deep learning" OR "machine learning") AND (pollution OR "ecosystem health") AND (marine)

Search string C: ("Artificial intelligence" OR "deep learning" OR "machine learning") AND (productivity OR phytoplankton) AND (marine)

Search string D: ("Artificial intelligence" OR "deep learning" OR "machine learning") AND ("marine ecosystem")

It should be noted that the quotation marks have the function of ensuring that terms composed of multiple words are searched together, thus preventing words from being considered individually. The publication date (of the scientific articles) is left open. The Scopus database search produces $98,150,40$, and 102 results respectively, for each query. The results are exported as a list into a spreadsheet, which makes an overall set of 396 papers (see Figure 1). The 396 papers screen and records excluded from the review process, if there are not any journal articles that are peer-reviewed, available online, and written in English language. This excludes 162 papers. This stage gives us 234 papers. 


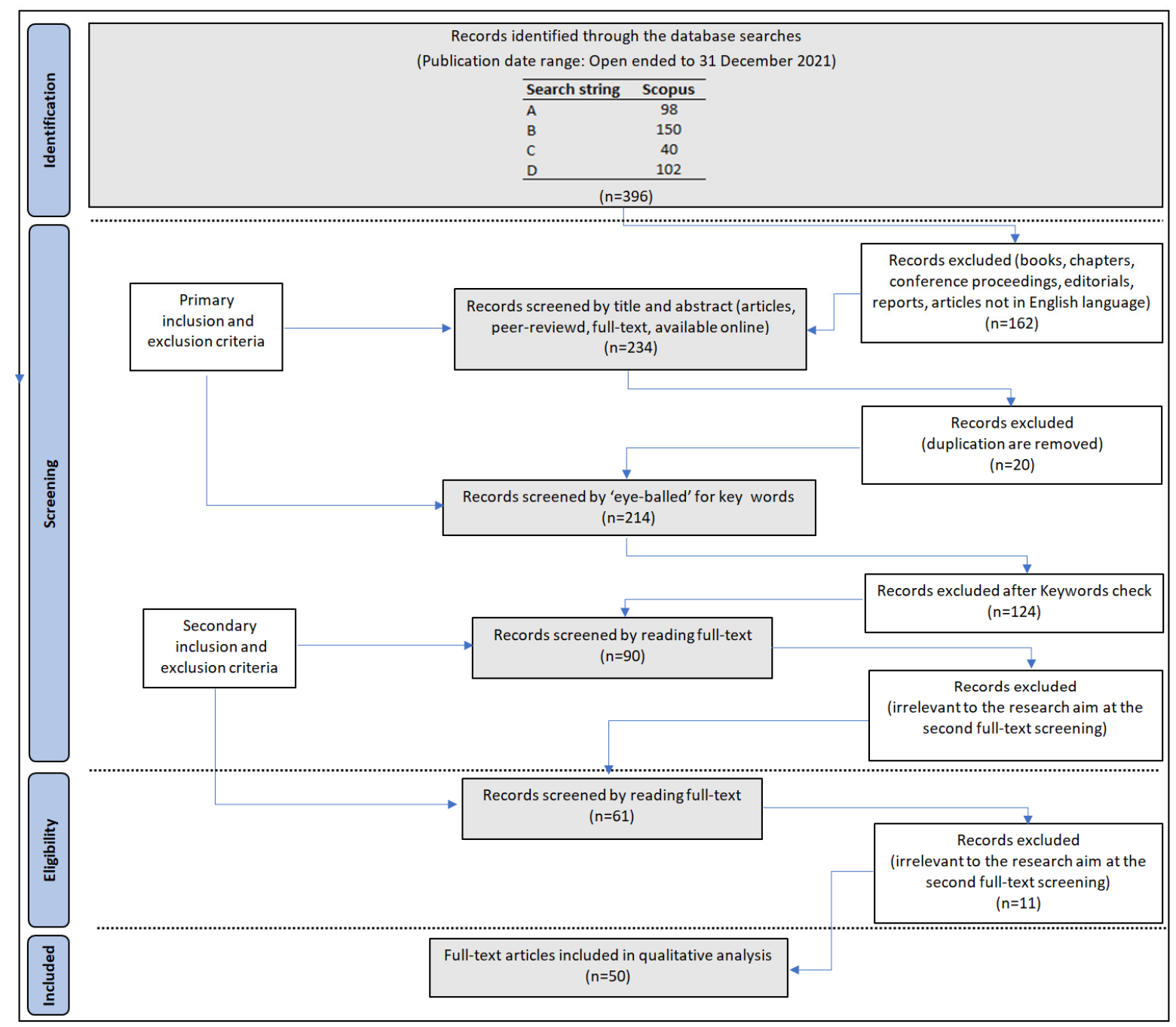

Figure 1. Literature selection procedure.

In Stage 2 (conducting the review stage), involves carrying out the review of relevant articles $[7,8,13-15]$. Initially, the dataset in the spreadsheet subjected to a round of duplicate removal $(n=20)$, which produces an overall set of 214 papers. Thereafter, specific criteria for secondary inclusion and exclusion of papers are applied. The first is to 'eye-ball', to ensure the articles are consistent with the keywords search. "Artificial intelligence (AI)", "machine learning", or "deep learning" should be found in the abstract, title, or authors' keywords. This exclusion brings us to a total of 90 papers. We then apply two rounds of exclusion. The full-text of the selected 90 articles are read to determine the relevance with respect to the aim of our systematic review. The result of Stage 2 comes with a narrowing down to 61 articles $(6,22,8$, and 25 for each query).

The first two authors of our paper read the resulting corpus of the articles and further examine them whether they are meaningfully related to the area of marine AI-inspired fishery. This step results in the inclusion of papers only related to AI. We include articles like a paper on primary production appraisals as relevant for our review, as such an article not only communicate understanding of the dynamics of this relationship with oceanic food webs, energy process carbon cycle and earth's climate, but also provides an analysis ecological processes like fish resources [16]. We exclude scientific articles that do not have smart and sustainable fishery as its core, such as a paper on oil spillage classification in which scenario analysis is the core of the paper, rather than machine learning in fishery systems [17]. This selection criterion further narrowed down our result to 50 . 
Moreover, we perform a reference check of these 50 papers. This step follows the same criteria for secondary inclusion and exclusion of papers. The first is to eye-ball, to ensure articles are consistent with the keywords search, "artificial intelligence (AI)", "machine learning", or "deep learning" that should be found in the abstract, title, or authors" keywords. Second, the full text of the articles is read to determine the relevance concerning the aim of the study and the result. With the inclusion of additional literature identified by the authors and peer reviewers, the total number of reviewed, cited, and quoted references is increased to 66 literature pieces.

The systematic review relies on a descriptive analysis of results. Qualitative techniques of pattern matching and explanation building are adopted to descriptively categorize the journal articles under specific categories [18]. The categorization of the reviewed literature under specific themes is done in four steps. The criteria for formation of the themes is presented in Table 1. Firstly, the AI techniques that are directly related to fish/fishery raised in the reviewed materials are tabulated, highlighting the major contribution of AI on the sustainability of fish stock. Secondly, the most important themes to best categorize the reviewed literature, in relation to the research aim, are determined. To conduct the systematic review and reduce human error, we use a data-extraction form as a repository for general (authors, title, journal) and specific (fish/fishing, pollution, primary production, policy/government) themes. Then, these specific themes are crossed-checked with AI for sustainability [19], with the major themes on the investigated topics being investigated. Thereby the categorization is finalized under three research themes, which are fish/fisheries, fishers/fishing fleets, and policy (see Figure 2).

Table 1. Selection criteria for formulating categories.

\section{Selection Criteria}

1. Determine the AI techniques of counting fish or directly related to fish abundance by using the eye-balling technique;

2. Identify the suitable literature pieces focusing on AI and at least one module in LMEs approach after reading the full-text;

3. Narrow down the selected categories and review the reliability of these against LMEs approach;

4. Shortlist the categories and crosschecked crossed-checked with fishery system components;

5. Review the shortlisted categories by going through the selected and reviewed literature one more time;

6. Confirm the selection and finalize the classification of the categories;

7. Place the reviewed literature pieces under the determined categories.

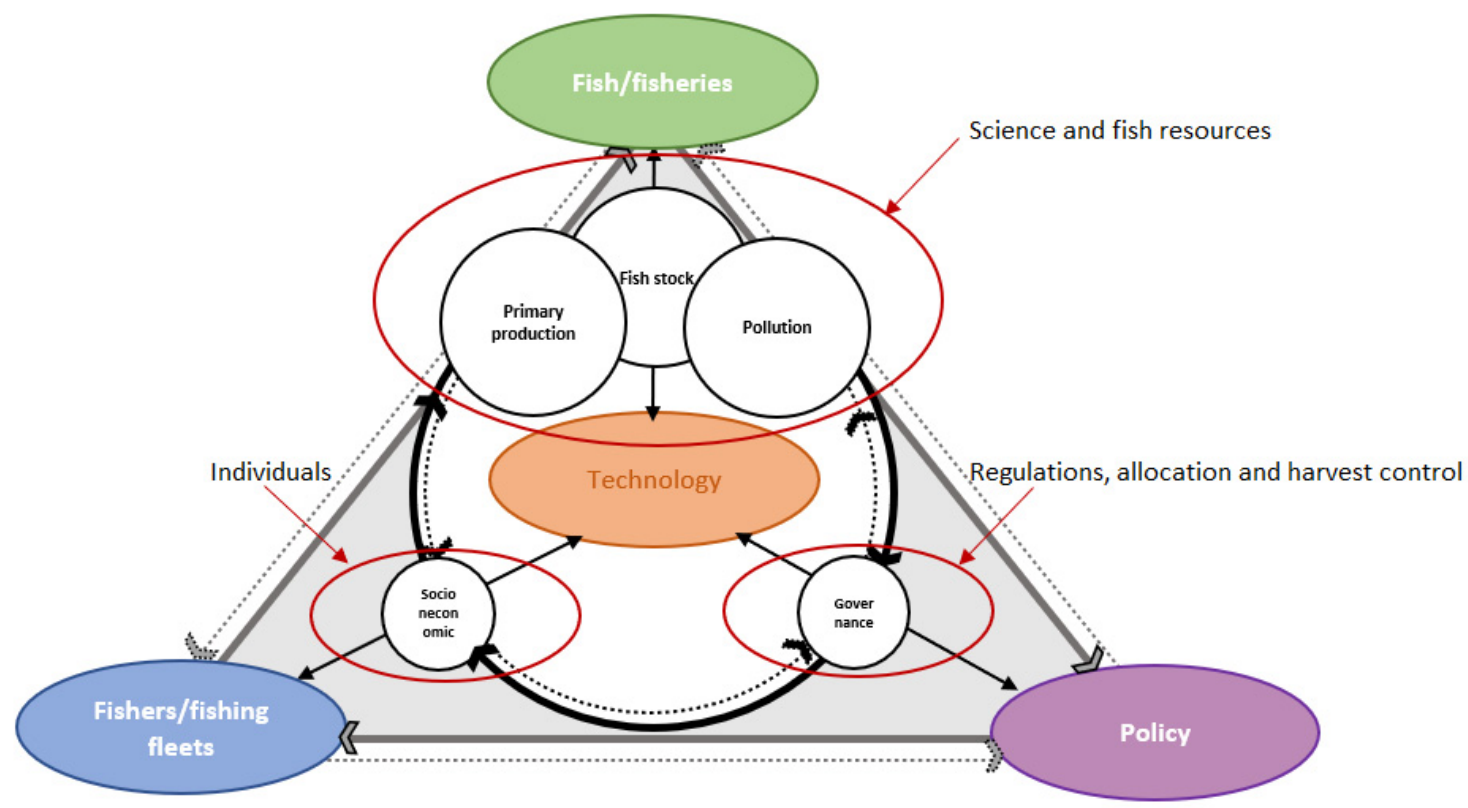

Figure 2. AI for sustainability in the context of fishery systems adopted from [19]. 
In Stage 3 (reporting and dissemination stage), the work focuses on writing up and presenting our findings in the format of a literature review paper. The list of the 66 papers can be found in Appendix A. At the write-up stage, other publications on the topic are also incorporated as additional supporting literature evidence to better analyze the topic and elaborate the overall findings.

\section{Results: General Observation}

\subsection{Distribution of Articles by Year of Publication}

Based on the results obtained in the systematic review, we note a growth trend in the number of publications related to AI in fishery systems since 2011 and before, special emphasis from 2017/2018 onwards, as shown in Figure 3. One of the earliest studies on intelligent system for fish catch prediction and allowable catch evaluation was from Sazonova et al. [20] and environmental monitoring was from Ricketts [21].

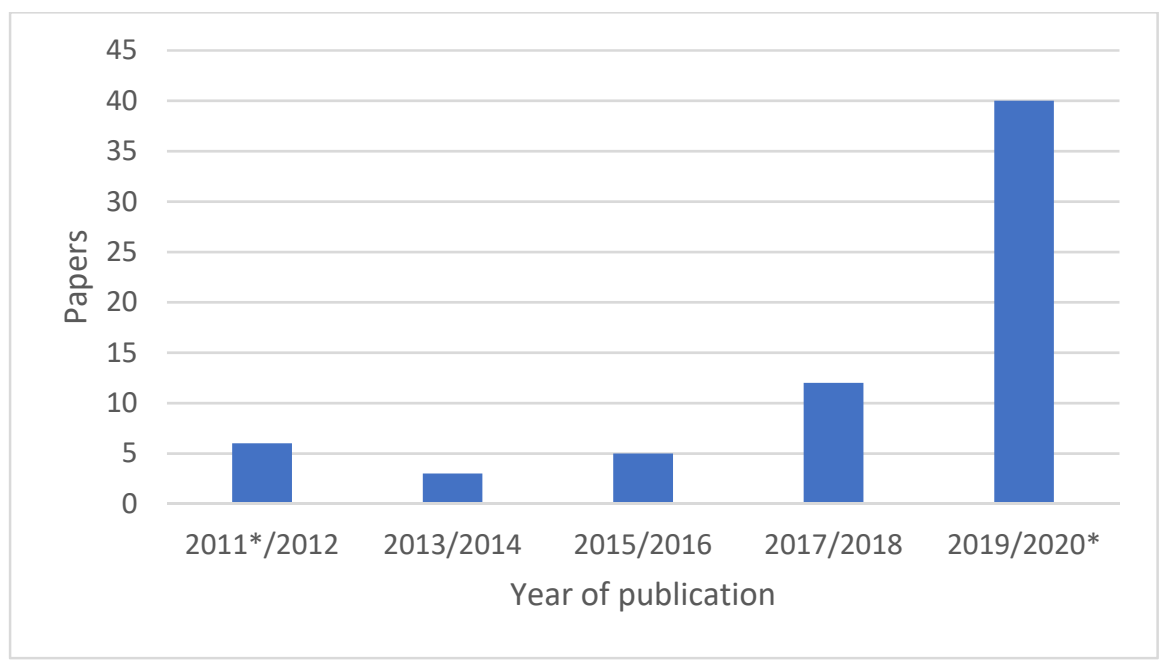

Figure 3. Number of reviewed articles by year of publication.

We observe an increase of $140 \%$ in the number of published papers in $2017 / 2018$. We observe an expressive increase of $233 \%$ of published papers in 2019/2020, until the end of 2020. The amount of published papers in recent years evidences increased discussion of the topic AI applied to fishery systems. It should be noted that the asterisks marks in Figure 3 have the function of indicating before 2011 and until the end of 2020.

\subsection{Distribution of Papers by Location of Large Marine Ecosystems}

Among the reviewed 66 articles, 39 of them include a location focus across (Figure 4).

Articles not only include a location focus but also point at different LMEs. Among the reviewed articles that outline a location, seven include LME \#26 (the Mediterranean Sea) and three contained LME \#48 (the Yellow Sea). A total of 24 LMEs were represented in the reviewed articles.

\subsection{Distributions of Papers by Authors' Affiliation}

The geographical distribution of authors (Table 2) shows that the topic of AI in fishery systems has attracted the interest of scholars worldwide. 


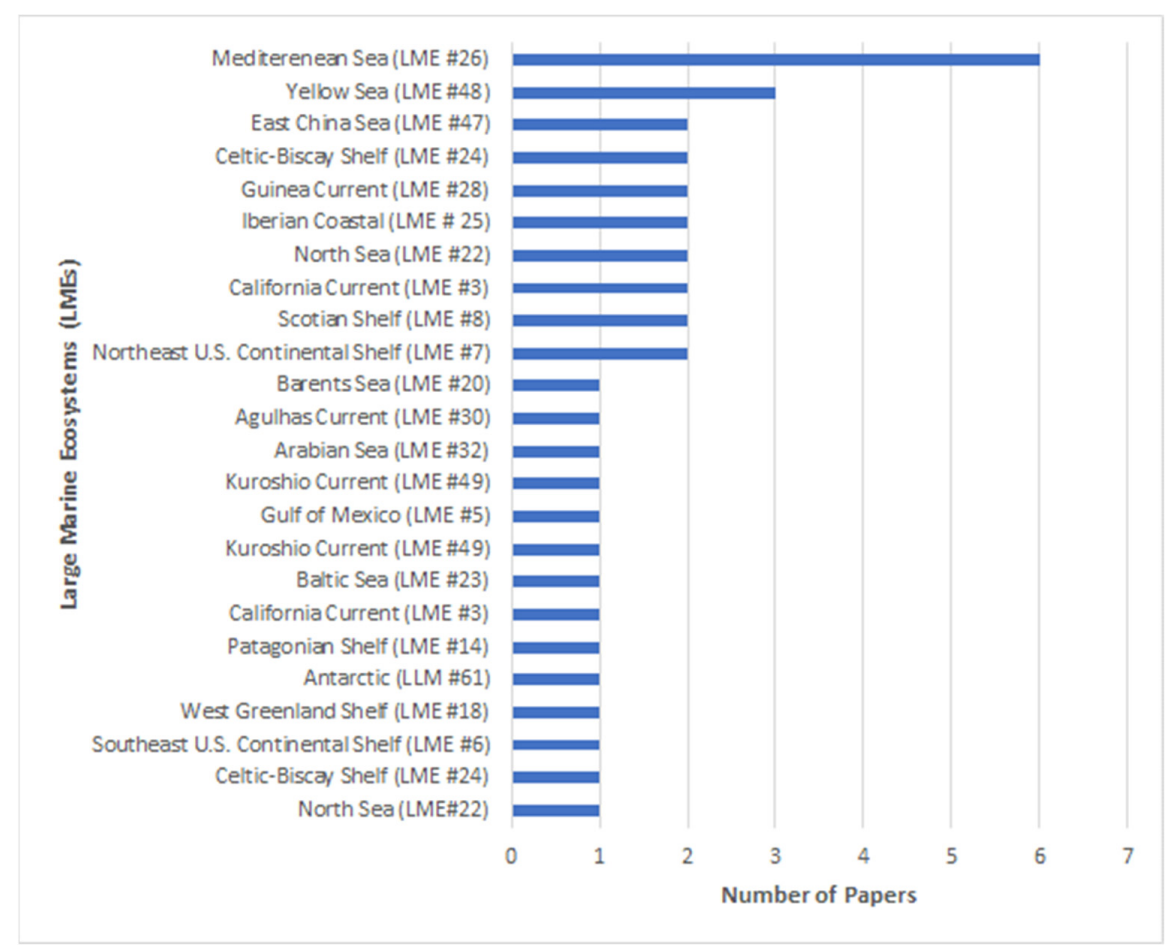

Figure 4. Number of revised articles by LMEs.

Table 2. Number of countries to which authors of reviewed articles belong.

\begin{tabular}{|c|c|c|c|}
\hline No & Geogrraphical Area (Affiliation) & Number of Authors & Example of Papers \\
\hline 1 & China & 60 & Ju and Xue (2020)/Jiao et al. (2019) \\
\hline 2 & Italy & 44 & Marini et al. (2018)/Lumini \& Nanni (2019) \\
\hline 3 & USA & 39 & De Laurentiis et al. (2020)/Fannjiang et al. (2019) \\
\hline 4 & Australia & 23 & Ditria et al. (2020)/Lopez-Marcano et al. (2020) \\
\hline 5 & Spain & 20 & Lopez-vazquez (2020)/Pérez-Ortiz et al. (2016) \\
\hline 6 & Japan & 15 & Watanabe et al. (2019)/Asakura et al. (2018) \\
\hline 7 & France & 12 & Villon et al. (2018)/Busseni et al. (2020) \\
\hline 8 & Canada & 11 & Knudby et al. (2010)/Ricketts (1992) \\
\hline 9 & Pakistan & 10 & Jalal et al. (2020)/Saddiqui et al. (2018) \\
\hline 10 & UK & 9 & Qiu et al. (2018) \\
\hline 11 & Greece & 8 & Keramitsoglou et al. (2006)/Tamvakis et al. (2014) \\
\hline 12 & Russia & 8 & Bukin et al. (2020) \\
\hline 13 & Sweden & 7 & Lehikoinen et al. (2019) \\
\hline 14 & Malaysia & 6 & Al-Ruzouq et al. (2020)/Temitope Yekeen et al. (2020) \\
\hline 15 & Germany & 5 & Dunker et al. (2018) \\
\hline 16 & UAE & 5 & Al-Ruzouq et al. (2020) \\
\hline 17 & Portugal & 5 & Pais et al. (2013) \\
\hline 18 & Croatia & 4 & Lorencin et al. (2019) \\
\hline 19 & South Korea & 4 & Kim et al. (2013) \\
\hline 20 & Uruguay & 3 & Bourel et al. (2017) \\
\hline 21 & Cyprus & 3 & Kylili et al. (2020) \\
\hline 22 & Iran & 3 & Banan et al. (2020) \\
\hline 23 & Netherlands & 2 & Boom et al. (2016) \\
\hline 24 & Philippines & 2 & Laboa et al. (2019) \\
\hline 25 & Thailand & 2 & Chuaysi \& Kiattisin (2020) \\
\hline 26 & Hong Kong & 2 & Chen et al. (2020) \\
\hline 27 & Norway & 2 & Budka et al. (2010) \\
\hline 28 & Bahrain & 2 & Albalooshi et al. (2018) \\
\hline 29 & Argentina & 2 & Pan et al. (2020) \\
\hline 30 & New Zealand & 2 & DiBattista et al. (2020) \\
\hline 31 & Poland & 1 & De souza et al. (2016) \\
\hline
\end{tabular}


Institutions in the Mediterranean regions of Europe (Italy and Spain, with 44 and 20 authors, respectively), and in Asian areas (Mainland China with 60 authors) are the most contributors. This spread emphasize geographical distribution of case studies (e.g., the Mediterranean Sea) which is the most popular location for research on AI in fishery systems.

\section{Results: Content Analysis}

This section introduces the results of the content analysis of the papers. This section aims to explore the contribution of AI to the sustainable fishery. First, we explore the smart fishery concept in categorized papers under (a) AI and fish/fishery, (b) AI and fishers / fishing fleets, and (c) AI and policy issues. Second, we discuss how smart fishery and sustainable fishery are related.

\subsection{Analysis of Smart Fishery Concept \\ 4.1.1. AI and Monitoring Fish Stock}

After reviewing the 66 scientific articles, we categorize them under AI and smart fishery if they directly contribute to fish/fishery which leads to 22 papers (see Table 3). The papers categorized under fishery resources are those that provide insights directly into contribution of AI in counting fish species [22-24]. There is an agreed advantages of AI for counting fish species [24-27]. Segmentation, detection, and classification of fish stocks within the marine ecosystems allow researchers to gather information regarding fish abundance [28-31].

In several articles, automation of classification is a key topic [32,33]. AI technologies are used in automation of fish classification procedures. Some articles include a focus on fish detection systems. Such systems are based on deep network architectures for robustly detecting and counting fish objects, under a variety of benthic background and illumination conditions [24,34]. While overlaps exist between classification, detection, and identification of fish stock, in practice, these automation themes have the same bottom line. Data on species composition and abundance distribution of fish species have considerable importance for monitoring the status and health of fish assemblages $[26,35,36]$. The view on automation include smart fishery as resource classification, identification, and detection, to assess fish abundance. As mentioned in one of the reviewed papers, fish abundance is one of the most unsustainable reasons for the global and national fishery [37].

In the reviewed articles, AI-inspired smart fishery for sustainability is not only linked to fish stock monitoring. Sustainable fishery is also related to environmental monitoring, which is reflected in the overlap of papers (see Table 4). Kylili et al. [38] (p. 42632) locate the scope of smart fishery in "epidemic of plastics entering the sea warrants urgent action if humanity is to stave off a collapse in fish stocks". They demonstrate that pollution is an urgent and necessary consideration regarding fish abundance. Furthermore, oil spills on seas and oceans - a major source of maritime and ocean pollution due to anthropogenic activities and the growing demand for oil and maritime transport capacity-pose a deleterious effect on aquatic and wildlife $[39,40]$. This understanding is also shared by Song et al. [41], who suggest that marine oil spills often result in large-scale marine pollution and seriously endangers the marine ecosystems and environment and fisheries. Moreover, global surface temperature rise comes with the urgent need to study the impacts of future climate change on fisheries [42]. 
Table 3. Literature on fish classification and abundance estimate.

\begin{tabular}{|c|c|c|c|c|c|c|}
\hline No & Author & Year & Title & Journal & Location & Theme \\
\hline 1 & Alshdaifat et al. & 2020 & $\begin{array}{l}\text { Improved deep learning framework for fish segmentation } \\
\text { in underwater videos }\end{array}$ & Ecological Informatics & $\mathrm{N} / \mathrm{A}$ & Fish segmentation \\
\hline 2 & Banan et al. & 2020 & $\begin{array}{l}\text { Deep learning-based appearance features extraction for } \\
\text { automated carp species identification }\end{array}$ & $\begin{array}{l}\text { Aquacultural } \\
\text { Engineering }\end{array}$ & $\mathrm{N} / \mathrm{A}$ & $\begin{array}{l}\text { Fish species } \\
\text { identification }\end{array}$ \\
\hline 3 & Ditria et al. & 2020 & $\begin{array}{l}\text { Automating the Analysis of Fish Abundance Using Object } \\
\text { Detection: Optimizing Animal Ecology With Deep } \\
\text { Learning }\end{array}$ & $\begin{array}{l}\text { Frontiers in Marine } \\
\text { Science }\end{array}$ & $\begin{array}{l}\text { Northeast Australian } \\
\text { Shelf-Great Barrier Reef } \\
\text { (LME \#40) }\end{array}$ & $\begin{array}{l}\text { Abundance of fish } \\
\text { species }\end{array}$ \\
\hline 4 & Jalal et al. & 2020 & $\begin{array}{l}\text { Fish detection and species classification in underwater } \\
\text { environments using deep learning with temporal } \\
\text { information }\end{array}$ & Ecological Informatics & $\begin{array}{l}\text { South China Sea (LME \#36) } \\
\text { \& West-Central Australian } \\
\text { Shelf (LME \#44) }\end{array}$ & $\begin{array}{l}\text { Abundance of fish } \\
\text { species }\end{array}$ \\
\hline 5 & Li et al. & 2020 & $\begin{array}{l}\text { Model-based unsupervised clustering for distinguishing } \\
\text { Cuvier's and Gervais' beaked whales in acoustic data }\end{array}$ & Ecological Informatics & Gulf of Mexico (LME \#5) & $\begin{array}{l}\text { Whale's regional } \\
\text { distribution }\end{array}$ \\
\hline 6 & Lopez-vazquez & 2020 & $\begin{array}{l}\text { Video image enhancement and machine learning pipeline } \\
\text { for underwater animal detection and classification at } \\
\text { cabled observatories }\end{array}$ & Sensors (Switzerland) & Barents Sea (LME \#20) & $\begin{array}{l}\text { Classification of different } \\
\text { species }\end{array}$ \\
\hline 7 & Lopez-Marcano et al. & 2020 & $\begin{array}{l}\text { The slow rise of technology: Computer vision techniques } \\
\text { in fish population connectivity }\end{array}$ & $\begin{array}{l}\text { Aquatic Conservation: } \\
\text { Marine and Freshwater } \\
\text { Ecosystems }\end{array}$ & $\mathrm{N} / \mathrm{A}$ & Fish connectivity \\
\hline 9 & Raza \& Hong & 2020 & $\begin{array}{l}\text { Fast and accurate fish detection design with improved } \\
\text { yolo-v3 model and transfer learning }\end{array}$ & $\begin{array}{l}\text { International Journal of } \\
\text { Advanced Computer } \\
\text { Science and Applications }\end{array}$ & $\mathrm{N} / \mathrm{A}$ & Fish detection \\
\hline 10 & Laboa et al. & 2019 & $\begin{array}{l}\text { Cascaded deep network systems with linked ensemble } \\
\text { components for underwater fish detection in the wild }\end{array}$ & Ecological Informatics & $\mathrm{N} / \mathrm{A}$ & Fish detection \\
\hline 11 & Asakura et al. & 2018 & $\begin{array}{l}\text { Regional feature extraction of various fishes based on } \\
\text { chemical and microbial variable selection using machine } \\
\text { learning }\end{array}$ & Analytical Methods & Kuroshio Current (LME \#49) & Fish classification \\
\hline 12 & Marini et al. & 2018 & $\begin{array}{l}\text { Tracking Fish Abundance by Underwater Image } \\
\text { Recognition }\end{array}$ & Scientific Reports & Mediterenean Sea (LME \#26) & Fish abundance \\
\hline 13 & Meng et al. & 2018 & $\begin{array}{l}\text { Underwater-Drone with Panoramic Camera for Automatic } \\
\text { Fish Recognition Based on Deep Learning }\end{array}$ & IEEE Access & $\mathrm{N} / \mathrm{A}$ & Fish recognition \\
\hline 14 & Qiu et al. & 2018 & $\begin{array}{l}\text { Improving transfer learning and squeeze- and } \\
\text { excitation-networks for small-scale fine-grained fish image } \\
\text { classification }\end{array}$ & IEEE Access & Mediterenean Sea (LME \#26) & Fish classification \\
\hline
\end{tabular}


Table 3. Cont

\begin{tabular}{|c|c|c|c|c|c|c|}
\hline No & Author & Year & Title & Journal & Location & Theme \\
\hline 15 & Saddiqui et al. & 2018 & $\begin{array}{l}\text { Automatic fish species classification in underwater videos: } \\
\text { Exploiting pre-trained deep neural network models to } \\
\text { compensate for limited labelled data }\end{array}$ & $\begin{array}{l}\text { ICES Journal of Marine } \\
\text { Science }\end{array}$ & $\begin{array}{l}\text { West-Central Australian } \\
\text { Shelf (LME \#44) }\end{array}$ & Fish species classification \\
\hline 16 & Villon et al. & 2018 & $\begin{array}{l}\text { A Deep learning method for accurate and fast } \\
\text { identification of coral reef fishes in underwater images }\end{array}$ & Ecological Informatics & Agulhas Current (LME \#30) & Fish identification \\
\hline 17 & Boom et al. & 2016 & $\begin{array}{l}\text { Uncertainty-aware estimation of population abundance } \\
\text { using machine learning }\end{array}$ & Multimedia Systems & $\mathrm{N} / \mathrm{A}$ & Fish abundance \\
\hline 18 & Pérez-Ortiz et al. & 2016 & $\begin{array}{l}\text { On the Use of Nominal and Ordinal Classifiers for the } \\
\text { Discrimination of States of Development in Fish Oocytes }\end{array}$ & $\begin{array}{l}\text { Neural Processing } \\
\text { Letters }\end{array}$ & $\mathrm{N} / \mathrm{A}$ & Fish classification \\
\hline 19 & Qin et al. & 2016 & $\begin{array}{l}\text { DeepFish: Accurate underwater live fish recognition with } \\
\text { a deep architecture }\end{array}$ & Neurocomputing & $\mathrm{N} / \mathrm{A}$ & Fish recognition \\
\hline 20 & Salman et al. & 2016 & $\begin{array}{l}\text { Fish species classification in unconstrained underwater } \\
\text { environments based on deep learning }\end{array}$ & $\begin{array}{l}\text { Limnology and } \\
\text { Oceanography: Methods }\end{array}$ & $\mathrm{N} / \mathrm{A}$ & Fish species classification \\
\hline 21 & Pais et al. & 2013 & $\begin{array}{l}\text { Seeking functional homogeneity: A framework for } \\
\text { definition and classification of fish assemblage types to } \\
\text { support assessment tools on temperate reefs }\end{array}$ & Ecological Indicators & $\begin{array}{l}\text { North Sea (LME \#22), } \\
\text { Iberian Coastal (LME \# 25), } \\
\text { Mediterranean Sea (LME } \\
\text { \#26), Guinea Current (LME } \\
\text { \#28), Celtic-Biscay Shelf } \\
\text { (LME \#24) }\end{array}$ & $\begin{array}{l}\text { Classification of fish } \\
\text { assemblage types }\end{array}$ \\
\hline
\end{tabular}


Table 4. Literature on monitoring marine environment and ecosystem health.

\begin{tabular}{|c|c|c|c|c|c|c|}
\hline No & Author & Year & Title & Journal & Location & Theme \\
\hline 1 & Kylili et al. & 2020 & $\begin{array}{l}\text { An intelligent way for discerning plastics at the } \\
\text { shorelines and the seas }\end{array}$ & $\begin{array}{l}\text { Environmental Science } \\
\text { and Pollution Research }\end{array}$ & $\mathrm{N} / \mathrm{A}$ & $\begin{array}{l}\text { Deberis and plastic } \\
\text { recognition }\end{array}$ \\
\hline 2 & Al-Ruzouq et al. & 2020 & $\begin{array}{l}\text { Sensors, features, and machine learning for oil spill } \\
\text { detection and monitoring: A review }\end{array}$ & Remote Sensing & $\begin{array}{l}\text { Arabian Sea (LME \#32), Agulhas } \\
\text { Current (LME \#30) }\end{array}$ & Oil spill detention \\
\hline 3 & Fanelli et al. & 2020 & $\begin{array}{l}\text { Towards naples ecological research for augmented } \\
\text { observatories (NEREA): The NEREA-fix module, a } \\
\text { stand-alone platform for long-term deep-sea } \\
\text { ecosystem monitoring }\end{array}$ & Sensors (Switzerland) & Mediterranean Sea (LME \#26) & Primary productioin \\
\hline 5 & Li et al. & 2020 & $\begin{array}{l}\text { Developing a microscopic image dataset in support of } \\
\text { intelligent phytoplankton detection using deep } \\
\text { learning }\end{array}$ & $\begin{array}{l}\text { ICES Journal of Marine } \\
\text { Science }\end{array}$ & Yellow Sea (LME \#48) & Primary productioin \\
\hline 6 & Fannjiang et al. & 2019 & $\begin{array}{l}\text { Augmenting biologging with supervised machine } \\
\text { learning to study in situ behavior of the medusa } \\
\text { Chrysaora fuscescens }\end{array}$ & $\begin{array}{l}\text { Journal of Experimental } \\
\text { Biology }\end{array}$ & California Current (LME \#3) & Primary productioin \\
\hline 7 & Franceschini et al. & 2019 & $\begin{array}{l}\text { Rummaging through the bin: Modelling marine litter } \\
\text { distribution using Artificial Neural Networks }\end{array}$ & $\begin{array}{l}\text { Marine Pollution } \\
\text { Bulletin }\end{array}$ & Mediterranean Sea (LME \#26) & $\begin{array}{l}\text { Deberis and plastic } \\
\text { recognition }\end{array}$ \\
\hline 8 & Cantorna et al. & 2019 & $\begin{array}{l}\text { Oil spill segmentation in SAR images using } \\
\text { convolutional neural networks. A comparative } \\
\text { analysis with clustering and logistic regression } \\
\text { algorithms }\end{array}$ & $\begin{array}{l}\text { Applied Soft Computing } \\
\text { Journal }\end{array}$ & $\mathrm{N} / \mathrm{A}$ & Oil spill segmentation \\
\hline 9 & Watanabe et al. & 2019 & $\begin{array}{l}\text { Underwater and airborne monitoring of marine } \\
\text { ecosystems and debris }\end{array}$ & $\begin{array}{l}\text { Journal of Applied } \\
\text { Remote Sensing }\end{array}$ & $\mathrm{N} / \mathrm{A}$ & $\begin{array}{l}\text { Deberis and plastic } \\
\text { recognition }\end{array}$ \\
\hline 10 & Schmid et al. & 2018 & $\begin{array}{l}\text { Lipid load triggers migration to diapause in Arctic } \\
\text { Calanus copepods-Insights from underwater } \\
\text { imaging }\end{array}$ & $\begin{array}{l}\text { Journal of Plankton } \\
\text { Research }\end{array}$ & West Greenland Shelf (LME \#18) & Primary productioin \\
\hline
\end{tabular}


Most reviewed papers use a location as an attempt to contextualize automation of environmental monitoring, which includes fish/fishery, primary production, and marine health. One of the locations that focuses on automation of fish stock monitoring includes the Mediterranean Sea to explore technological innovations $[43,44]$. The paper, by Fanelli et al. [45], include primary production as increasingly recognized as indispensable for the comprehension of the largest biome on Earth. Furthermore, a set of Artificial Neural Networks (ANN) are trained to both model the effect of environmental descriptors on litter distribution and estimate the amount of marine litter in the Central Mediterranean Sea [46]. Overall, it is noted that the Mediterranean Sea is the only LME that covers AI in the three environmental monitoring in the ecosystem-based approach, such as fish/fishery, primary production, and marine health. In return, this would help LMEs recycle nutrients to sustain anticipated production levels [47].

\subsubsection{AI and Fishing}

Fishing activity is an universal force that has extensive influence on catch monitoring across fishery systems at-sea [48]. There are diverse range of AI applications within fishing activity from evaluating economics of commercial fleets [49], electronic monitoring of catch and bycatch [50], detecting and forecasting fishing grounds [51], to simulating fishing vessel behavior [52]. From the reviewed papers, only two papers had touched upon AI technologies in fishing activities. Why there has been such a limited effort is difficult to pinpoint. Bradley et al. [1] mentions that one of the major challenge that may prevent the uptake and integration of new fishery-dependent data technologies across all fishery sectors is lack of trust and buy-in from fishers. For example, illegal fishing practices influence how fishers view annual decreases in their total allowable catch as putative and unnecessary, leading to controversy and feelings of distrust between fishery stakeholders [53]. The lack of fishers' trust seems to be as an obstacle for taking in AI technologies in fishery systems. De Souza et al. [54] and Chuaysi and Kiattisin [37] agree upon tracking fishing activities within the marine ecosystems, which allows researchers to gather information regarding allowable fish catch $[37,54]$. This in return is a useful step for monitoring illegal fishing activities.

Two reviewed articles focus on automation of monitoring of illegal fishery methods [46]. They base their scope of what might be considered AI technology for "tracing back to the source of catching with the existing data and technology", such as tracing massive catch by illegal catch methods. They argue that fishing vessels at sea provide information for tracing back to catch source at sea for seafood and improves the illegal, unreported, and unregulated (IUU) fishing, including transshipments at sea [37]. In this way, transparency of vessel movements would shed light on the geographic distribution of IUU fishing operations [37]. They emphasize that a key challenge in contemporary ecology and conservation management is the accurate tracking of the spatial distribution of various human impacts, such as fishing [37]. They stress that while important from a scientific perspective, there are also many other obvious applications of AI, including the monitoring of marine fisheries and the enforcement of spatial management measures, such as marine protected areas (MPAs), ecologically and biologically significant areas (EBSAs), as well as fisheries closure zones.

\subsubsection{AI and Policy Issues}

In our systematic review, various articles point at the critical importance of AI technological developments on one hand and policy response from governance actors on other hand. A total of 10 out of the 66 reviewed articles touch upon policies in general; and 3 out of them named a specific policy. These articles place their scope of AI-inspired fishery in policies. Multiple AI for sustainability scholars indicate that public policy is critically important for making AI technologies work for realizing the sustainable fishery (e.g., [19,55-57]). This indicates the existence of a major gap in research on policy intervention for AI for sustainable fishery systems. 
Reviewed articles indicate that fish detection and counting are crucial for policy formulation to effectively control fish harvesting and prevent stock depletion [24]. Salman et al. (2016) stresses that a timely warning to regulatory authorities and government bodies is necessary to implement and impose strict rules for preservation of endangered fish species. For example, the EU and the US have set up a transparency fisheries policy to fight against illegal fishing [37]. In the case of, for instance, oil spill detection, the government's regulatory agencies are responsible for documenting all spill incidents [58].

Among reviewed articles only two of them discuss the European Marine Strategy Framework Directive. The article, by [43], argues that increasing pressure on the marine environment has led to several policies that seek to improve the state of marine ecosystems and ensure the sustainable use of resources. Another reviewed article, by [44], points at changes in fish communities, especially regarding commercial species, considered under relevant international policy actions. And only one of the reviewed articles touches upon policies such as the Blue Growth call, which expects from AI technologies that they strengthen the marine industry and support the global monitoring of the marine environment [45].

Concerning the smart fishery concept, it appears that scholarly attention in AI-inspired fishery literature focusses mostly on automation of fishery resources monitoring, mainly detection, identification, and classification. Some papers list marine health and primary production, which are vital dimensions of sustainable fishery and would help LMEs recycle nutrients to sustain anticipated production levels. Very few reviewed articles refer to assessing individual needs, in particular the needs of fishers, from AI deployment in the fishery to response from governments through policy.

\subsection{Smart Fishery and Sustainable Fishery}

AI technologies increasingly play a dominant role in the automation of environmental monitoring, in particular fish/fishery dimension of ecosystem-based approach. Like the concept of the smart fishery in aquaculture that focuses on the role of technology in resource optimization [2], the emergent concept of the marine smart fishery draws upon the prominent role of artificial intelligence technologies in fish stock monitoring through segmentation, detection, and classification. The smart fishery at sea refers to a scientific field whose objective is to automate counting fish for monitoring the health of fish assemblages to may optimize fish catch. As stated in one of the reviewed articles by Stock et al. [59], however, sustainable fishery requires approaches that consider the combination of multiple stressors, and only then understanding where most urgent actions are needed to address impacts is possible. In the current advent of the making of the so-called 'Age of $\mathrm{AI}^{\prime}$ ', fishers' experiences, perceptions, practices and needs with regard to advanced AI technologies and the role of governments' AI strategies and their AI policy designs and implementations, need to be taken into account, if AI is to work effectively in the field of fishery [19].

Research on application of AI technologies in sustainable fishery is typically concerned with the development of AI techniques for the prediction of certain events, such as fish stock assessment. These smart fishery systems appear to be autonomous, i.e., they create outputs that affect people in ways that do not allow responsibility to be ascribed to human beings [60]. Equally central have been ambitions to control, through technological developments that deskill work through "automation" and hamper collective bargaining [61]. Conversely, breakdowns in direct communication and collaboration among scientists and fishers can create an 'accountability cascade' of blame, distrust, and dysfunction [48]. Further, AI technologies tend to focus on (or be used for) increasing efficiency in counting fish stock. By their very nature, they feed on data that can be measured and counted [62]. As in the case of AI-inspired smart fishery, all too often these scientific systems use data to justify the workings of the system but not to question or improve the system [62]. Even if the solutions are optimal from a mathematical point of view (given a certain range of selected parameters), additional research is typically needed to assess the long-term impact of such algorithms on equity and fairness [63]. Justice, for example, cannot just be 
something that individuals in one society, e.g., in the Mediterranean Sea inflicts upon the other. Machine learning and deep learning, for all their advances in language and logic, still struggle mightily with moral phenomena of justice and fairness; that is, they frequently enact injustice and bias [62]. This deficiency leads the AI research community to publish positive and often biased results apparent in the SGDs [19], in particular when it comes to target 14.5 on conserving coastal and marine areas [64]. Discovery of the detrimental aspects of AI may require long-term studies [19].

While governments and policies affect AI technological development in different areas through automation that need appropriate piloting and testing (e.g., in counting fish and environmental monitoring), they are not yet equipped by legislation and standards that governments provide to technology. There is a research gap in real-world applications of such systems, e.g., by governments [19]. So, instead of developing AI for sustainable fishery and optimizing it, researchers have to deal with a black box. To open it, we need to come to understand AI for sustainability, from (1) an interplay between technological developments on one side and needs of individuals, (2) response from governments, and (3) environmental resources and dynamics [19]. Consequently, researchers stress that it is essential to promote the development of initiatives to assess the societal, practical, and policy implications of AI technologies [65]. Scientific interest in these implications can help stakeholders to enjoy the benefits and opportunities of predicting and managing incidents and failure and improve efficiency and reliability created by effective implementation and use of AI technologies [3], while minimizing the risks of defining fuzzy responsibilities for individuals (e.g., fishers) to adopt and use AI [55].

New AI technologies are developing at a rapid phase, affecting the way fishers work through automation as well as the impact such technologies have on fishery systems. The problem is that neither the fishers' experiences, perceptions, practices, and needs connected with the embeddedness of AI in fishery systems, such as fairness and equity, nor AI strategies, policy design and implementations from governments seem to be supportive for enhancing sustainable fishery. Further research into the detrimental aspects of AI in fishery systems typically require long-term studies.

\section{Towards a Research Agenda for Sustainable Fishery in the Age of AI}

Our systematic review reveals that scientific enquiry into AI-inspired fishery systems at sea is still a field in its infancy. In line with Fosso et al. [3], our review shows a growing research emphasis on AI's technical aspects and surprisingly little research on the politicaladministrative aspects that shape sustainable fishery in the age of AI. We call for the development of a research stream that focusses on the societal aspect of making smart fishery more sustainable. The results of our systematic review enable us to identify some upcoming themes for future research in this context of an as yet limited focus on the intermingling's of $\mathrm{AI}$ and the political-administrative dimensions in smart fishery systems (Figure 5).

Our research agenda is based on the "building blocks" considered as essential in future studies that focus on making smart fishery more sustainable (i.e., AI technologies, endangered fish species, AI governance, and AI individual's needs), as highlighted in Section 4.1. Automation of environmental monitoring increasingly play a prominent role in ecosystem management. Such AI technologies may be beneficial for many different LMEs, but AI-inspired smart fishery requires both technological as well as political-administrative perspectives [60]. Learning AI-related policy-making tendencies may help in decision making that is less biased and better informed; and marked by lower degrees of oligarchical power abuse [55]. Future studies should take into account the underlying effects of specific political-administrative factors (such as governance constellations, power relations, the role of tech firms (AI firms), policy programs, policy entrepreneurs, decision making dynamics, etc.) that play a key role in making smart fishery more sustainable. Such efforts could strengthen the link between AI and their effect on the sustainable fishery, clarifying whether some AI technologies and generally accepted smart fishery (e.g., specific locations 
in Europe) have positive feedback on the sustainability of fish assemblage. A key future research question is how $\mathrm{AI}$ technologies can be designed and used to better monitor endangered fish species, and what is the role of political-administrative stakeholders in this?

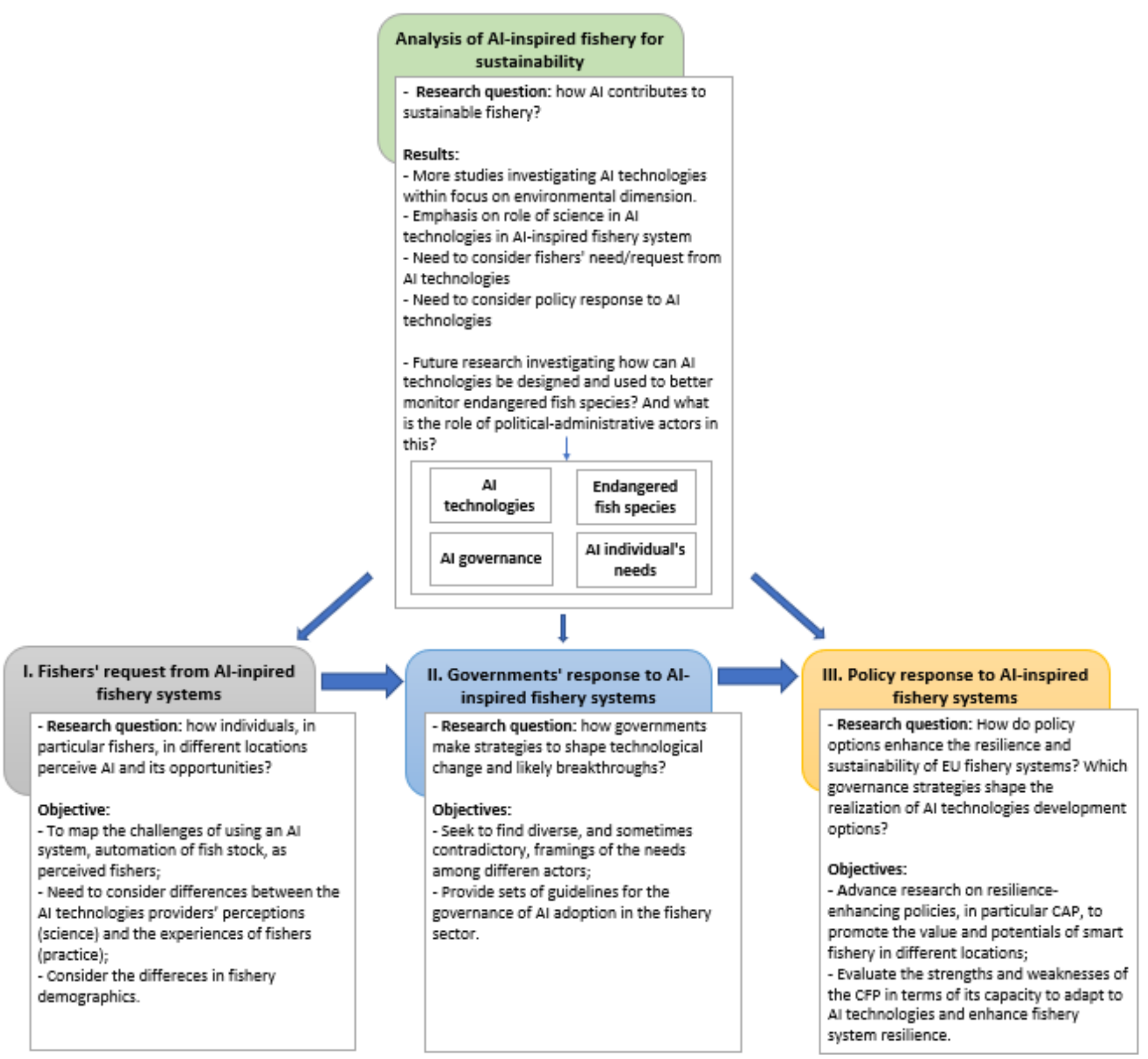

Figure 5. Research agenda.

Public policies impact AI technology deployment, such as automation of fishery resources monitoring. In our systematic review, the most frequently mentioned policy that calls for AI deployment in proposing changes in fish communities is the European Marine Strategy Framework Directive. Although such policies trigger technological development in many different LMEs like in the Mediterranean Sea, it is arguable that strengthening the relationship between policy perspectives and their effects on fishery systems can have an impact on both research and industry to strengthen the global monitoring of the marine environment. The concept of marine smart fishery needs further exploration and further research is necessary for defining specific guidelines for sustainable development in AI- 
inspired fishery systems. Further research on kinds of policy configuration in the age of AI is needed for developing understanding of how to make smart fishery more sustainable.

We call for future studies on how stakeholders, in particular fishers, perceive AI needs and its uncertainties. Fishers behave according to their perceptions and beliefs; and hence knowing their perceived AI needs, including justice and fairness [63], helps explaining decision making. Furthermore, recognizing the relationship between fishers and technologies comes with recognizing uncertainties associated with the advance of AI deployment [65]. This awareness creates values of care that constitute practices that seems necessary for making sustainable action possible. Sustainability transformation needs "radical, systemic shifts in [these] values and beliefs [and] patterns of social behaviour" [66]. In the context of sustainability transformation, it is a prompt to bring values of justice and normativity more firmly into the picture and to re-think how key concepts have to evolve [67].

The proposed question also calls for analyzing and developing fishery demographics. Although most reviewed articles point at practices for developing AI-inspired smart fishery technologies for advancing automation of fishery resources classification, a structured analysis of smart fishery systems and its practices is missing. We need a clearer understanding of these fishery systems, including the type of challenges (e.g., economic, environmental, social, and institutional) a system faces and how fishery systems can respond to these challenges. Systematization of these challenges according to a specific large marine ecosystem (e.g., the Mediterranean Sea, the North Atlantic Sea) is required to support practitioners in strategic planning and operations. To move beyond narrow "science-based" AI technical assessments [66] toward an understanding the differences between AI technology providers' perceptions and the experiences of fishers in the use of specific AI technologies should be considered in future enquiry into AI for sustainability. The ultimate aim of answering the question of how fishers experience and perceive AI and its uncertainties is to map the challenges of using AI technologies, and to evaluate fishers' needs from, and workings with, AI technologies to improve AI for sustainability in different fishery demographics.

Focusing on policy responses to AI-inspired fishery systems, it appears that AI technologies are not yet equipped by legislation and standards that governments provide for regulating AI. A key research theme is therefore to find out how governments make strategies to shape technological change and likely breakthroughs [55]. It has been widely recognized that smart fishery systems are highly political; its administrative systems are marked by complexity and ambiguity; and its alleged scientific advice, management, and policy are closely intertwined [68-71]. While governments and policies affect AI technological developments in different areas through automation that needs appropriate piloting and testing (e.g., in counting fish and environmental monitoring), little evidence as yet exists that demonstrates that governments possess a tangible strategy or depth of understanding to even begin to think on regulating AI with regard to smart fishery systems [55].

Finally, future studies may advance research on resilience-enhancing policies to promote the value and potentials of AI-inspired smart fishery in different locations. This in return may advance understanding of how the Common Fishery Policy (CFP) may respond to the AI-inspired fishery systems in becoming more sustainable. Concrete environmental problems certainly must be addressed in the here and now; and addressing them requires the expert input, efficient policymaking, and innovative technologies [67]. Especially, CFP supports the regional fishery systems to adapt to changing economic, social, and environmental circumstances. Insofar as this system structurally reproduces unsustainable patterns, however, these are not sufficient for smart fishery to become sustainable [67].

Here, the key characteristic of resilience-enhancing policies is often presented as having room for flexibility, multi-stakeholder deliberation, a wise balance between robustness and change [72]. A key upcoming research theme is to evaluate the strengths and weaknesses of the CFP (in its composition of the member states case studied developed in the first research proposal) in terms of its administrative capacity to adapt to AI technologies and enhance fishery systems resilience. How do policy options enhance the resilience and 
sustainability of EU fishery systems? Which governance strategies shape the realization of AI technologies development options?

\section{Concluding Remarks}

This review aimed to answer the question, "how AI contributes to the sustainable fishery?" The findings of our systematic literature review of the smart fishery concept reveal that scholarly attention in AI-inspired fishery literature focuses mostly on automation of fishery resources monitoring, yet fishers needs from AI deployment and policy response from governments received limited scholarly attention. However, sustainable fishery requires approaches that combine these aspects, and only then understanding where most urgent actions are needed to address impacts is possible. We need to come to understand AI for sustainability, from (1) an interplay between technological developments on one side and needs of individuals, (2) response from governments, and (3) environmental resources and dynamics [19]. This review contributes to the literature by highlighting the most investigated dimensions of AI for the sustainable fishery and identifying upcoming themes for future research on the sustainable fishery in the Age of AI.

In terms of future studies, we can see several areas in the political-administrative aspect of the AI-inspired fishery systems that would contribute to shaping a more sustainable fishery system. The first is around the perception of fishers on AI technologies. Knowing their perceived AI needs, such as equity, and fairness helps explaining decisions making and defining clear responsibilities to adopt and use AI in fishery systems. Understanding fishers' needs appear key for AI (and governments' AI strategies) to work effectively in the field of sustainable fishery. Further, public policy is critically important for making AI technologies work for realizing sustainable fishery (e.g., [19,55-57]). Existing AI strategies and AI developments optimize the efficient use of resources, but at present these are not equipped by the policy. A focus on understanding governments' strategies to shape technological change appears essential in AI for the sustainable fishery. The third proposed research stream is around resilience-enhancing policies. The CFP may respond to the AI-inspired fishery systems through economic, social, and environmental dimensions to becoming more sustainable. However, these are not sufficient for the smart fishery to become sustainable. Evaluating the strengths and weaknesses of the CFP in terms of its capacity to adapt to AI technologies and could be a key mechanism to enhance fishery systems resilience. We strongly believe that, given the sustainability challenges of fishery systems, the scientific community, as well as the stakeholders of fishery systems, need to better integrate around smart fishery, to negate and transcend the unsustainable smart fishery.

Author Contributions: Conceptualization, S.H.E.; methodology, S.H.E., M.O., and A.N.; validation, S.H.E., M.O., and A.N.; formal analysis, S.H.E.; investigation, S.H.E.; resources, S.H.E.; writingoriginal draft preparation, S.H.E.; writing - review and editing, S.H.E., M.O., and A.N.; visualization, S.H.E.; supervision, M.O. and A.N.; project administration, S.H.E. All authors have read and agreed to the published version of the manuscript.

Funding: This research received no external funding.

Data Availability Statement: The study did not report any data.

Conflicts of Interest: The authors declare no conflict of interest.

\section{Appendix A}

List of papers included in the systematic review (the other 32 papers can be found in Tables 3 and 4 in the text). 


\begin{tabular}{|c|c|c|}
\hline No & Literature & Title \\
\hline 1 & Bukin et al. (2020) & New solutions of laser-induced fluorescence for oil pollution monitoring at sea \\
\hline 2 & Busseni et al. (2020) & Large scale patterns of marine diatom richness: Drivers and trends in a changing ocean \\
\hline 3 & Chen et al. (2020) & A machine-learning approach to modeling picophytoplankton abundances in the South China Sea \\
\hline 4 & Chuaysi \& Kiattisin (2020) & Fishing Vessels Behavior Identification for Combating IUU Fishing: Enable Traceability at Sea \\
\hline 5 & D'Alelio et al. (2020) & Machine learning identifies a strong association between warming and reduced primary productivity in an oligotrophic ocean gyre \\
\hline 6 & De Laurentiis et al. (2020) & Deep Learning for Mineral and Biogenic Oil Slick Classification With Airborne Synthetic Aperture Radar Data \\
\hline 7 & DiBattista et al. (2020) & Environmental DNA can act as a biodiversity barometer of anthropogenic pressures in coastal ecosystems \\
\hline 8 & Liu et al. (2020) & Impact of Climate Change on Wintering Ground of Japanese Anchovy \\
\hline 9 & Li et al. (2020) & NASA NeMO-Net's Convolutional Neural Network: Mapping Marine Habitats with Spectrally Heterogeneous Remote Sensing Imagery \\
\hline 10 & Pan et al. (2020) & Environmental drivers of phytoplankton taxonomic composition in an Antarctic fjord \\
\hline 11 & Temitope Yekeen et al. (2020) & A novel deep learning instance segmentation model for automated marine oil spill detection \\
\hline 12 & Yu \& Du (2020) & A Machine-Learning-Based Model for Water Quality in Coastal Waters, Taking Dissolved Oxygen and Hypoxia in Chesapeake Bay as an Example \\
\hline 13 & Jiao et al. (2019) & A new approach to oil spill detection that combines deep learning with unmanned aerial vehicles \\
\hline 14 & González et al. (2019) & Automatic plankton quantification using deep features \\
\hline 15 & Lehikoinen et al. (2019) & Evaluating complex relationships between ecological indicators and environmental factors in the Baltic Sea: A machine learning approach \\
\hline 16 & Liu et al. (2019) & Semi-automatic oil spill detection on X-band marine radar images using texture analysis, machine learning, and adaptive thresholding \\
\hline 17 & Lorencin et al. (2019) & Marine objects recognition using convolutional neural networks (Prepoznavanje morskih objekata uporabom konvolucijskih neuronskih mreža) \\
\hline 19 & Ozigis et al. (2019) & Mapping terrestrial oil spill impact using machine learning random forest and Landsat 8 OLI imagery: a case site within the Niger Delta region of Nigeria \\
\hline 20 & Song et al. (2019) & A Novel Marine Oil Spillage Identification Scheme Based on Convolution Neural Network Feature Extraction from Fully Polarimetric SAR Imagery \\
\hline 21 & Pelta et al. (2019) & A machine learning approach to detect crude oil contamination in a real scenario using hyperspectral remote sensing \\
\hline 22 & Albalooshi et al. (2018) & Deep belief active contours (DBAC) with its application to oil spill segmentation from remotely sensed sea surface imagery \\
\hline 23 & Dunker et al. (2018) & Combining high-throughput imaging flow cytometry and deep learning for e-cient species and life-cycle stage identification of phytoplankton. \\
\hline 24 & Hu et al. (2018) & Comparison of machine learning techniques in inferring phytoplankton size classes \\
\hline 25 & Stock et al. (2018) & Mapping ecological indicators of human impact with statistical and machine learning methods: Tests on the California coast \\
\hline 26 & Bourel et al. (2017) & Consensus methods based on machine learning techniques for marine phytoplankton presence-absence prediction \\
\hline 27 & De souza et al. (2016) & Improving fishing pattern detection from satellite AIS using data mining and machine learning \\
\hline 28 & Tamvakis et al. (2014) & Optimizing biodiversity prediction from abiotic parameters \\
\hline 29 & Kim et al. (2013) & Machine learning approaches to coastal water quality monitoring using GOCI satellite data \\
\hline 30 & Budka et al. (2010) & Robust predictive modelling of water pollution using biomarker data \\
\hline 31 & Chau (2006) & A Review on Integration of Artificial Intelligence into Water Quality Modelling \\
\hline 32 & Keramitsoglou et al. (2006) & Automatic identification of oil spills on satellite images \\
\hline 33 & Kubat et al. (1998) & Machine Learning for the Detection of Oil Spills in Satellite Radar Images \\
\hline 34 & Ricketts (1992) & Current approaches in Geographic Information Systems for coastal management \\
\hline
\end{tabular}




\section{References}

1. Bradley, D.; Merrifield, M.; Miller, K.M.; LoMonico, S.; Wilson, J.R.; Gleason, M.G. Opportunities to improve fisheries management through innovative technology and advanced data systems. Fish Fish. 2019, 20, 564-583. [CrossRef]

2. Yang, X.; Zhang, S.; Liu, J.; Gao, Q.; Dong, S.; Zhou, C. Deep learning for smart fish farming: Applications, opportunities and challenges. Rev. Aquac. 2020, 13, 66-90. [CrossRef]

3. Fosso, K.; Wamba, S.; Bawack, R.; Guthrie, C.; Queiroz, M.; Carillo, K. Are we preparing for a good AI society? A bibliometric review and research agenda. SSRN Electron. J. 2021, 164, 120482. [CrossRef]

4. Peeters, R.; Schuilenburg, M. The Algorithmic Society, Technology, Power, and Knowledge; Routledge: London, UK, 2021.

5. Ossewaarde, M.; Gulenc, E. National Varieties of Artificial. Computer 2020, 53, 53-61. [CrossRef]

6. Mustafa, F.H. A Review of Smart Fish Farming Systems. J. Aquac. Eng. Fish. Res. 2016, 2, 193-200. [CrossRef]

7. Moher, D.; Liberati, A.; Tetzlaff, J.; Altman, D.G. Preferred reporting items for systematic reviews and meta-analyses: The PRISMA statement. J. Clin. Epidemiol. 2009, 62, 1006-1012. [CrossRef] [PubMed]

8. Navarro, A.; Costa, E.; Pereira, N. A Systematic Review of IoT Solutions for Smart Farming. Sensors 2020, 20, 4231. [CrossRef] [PubMed]

9. Yigitcanlar, T.; Kamruzzaman, M.; Foth, M.; Sabatini-Marques, J.; Da-Costa, E.; Ioppolo, G. Can cities become smart without being sustainable? A systematic review of the literature. Sustain. Cities Soc. 2019, 45, 348-365. [CrossRef]

10. Sarkis-Onofre, R.; Catalá-López, F.; Aromataris, E.; Lockwood, C. How to properly use the PRISMA Statement. Syst. Rev. 2021, 10,1-3. [CrossRef]

11. Wolfert, S.; Ge, L.; Verdouw, C.; Bogaardt, M.-J. Big Data in Smart Farming-A review. Agric. Syst. 2017, 153, 69-80. [CrossRef]

12. Sherman, K. Manuscript in Press at Encyclopedia of Ocean. Sciences; Elsevier Science: Amsterdam, The Netherlands, 2016; No. Sdg 14 .

13. Yigitcanlar, T.; DeSouza, K.C.; Butler, L.; Roozkhosh, F. Contributions and risks of artificial intelligence (AI) in building smarter cities: Insights from a systematic review of the literature. Energies 2020, 13, 1473. [CrossRef]

14. Rathnayake, C.; Joshi, S.; Cerratto-Pargman, T. Mapping the current landscape of citizen-driven environmental monitoring: A systematic literature review. Sustain. Sci. Pract. Policy 2020, 16, 326-334. [CrossRef]

15. Mukendi, A.; Davies, I.; Glozer, S.; McDonagh, P. Sustainable fashion: Current and future research directions. Eur. J. Mark. 2020, 54, 2873-2909. [CrossRef]

16. Mattei, F.; Scardi, M. Embedding ecological knowledge into artificial neural network training: A marine phytoplankton primary production model case study. Ecol. Modell. 2020, 421, 108985. [CrossRef]

17. Liang, X.; Zhen, Z.; Song, Y.; Jian, L.; Song, D.; Songa, D. Pol-SAR Based Oil Spillage Classification With Various Scenarios of Prior Knowledge. IEEE Access 2019, 7, 66895-66909. [CrossRef]

18. Yin, R.K. Qualitative Research from Start to Finish; Guilford Publications: New York, NY, USA, 2011.

19. Vinuesa, R.; Azizpour, H.; Leite, I.; Balaam, M.; Dignum, V.; Domisch, S.; Felländer, A.; Langhans, S.D.; Tegmark, M.; Nerini, F.F. The role of artificial intelligence in achieving the Sustainable Development Goals. Nat. Commun. 2020, 11, 1-10. [CrossRef]

20. Sazonova, L.; Osipov, G.; Godovnikov, M. Godovnikov Intelligent system for fish stock prediction and allowable catch evaluation. Environ. Model. Softw. 1999, 14, 391-399. [CrossRef]

21. Ricketts, P.J. Current approaches in Geographic Information Systems for coastal management. Mar. Pollut. Bull. 1992, 25, 82-87. [CrossRef]

22. Boom, B.J.; Beauxis-Aussalet, E.; Hardman, L.; Fisher, R.B. Uncertainty-aware estimation of population abundance using machine learning. Multimed. Syst. 2016, 22, 737-749. [CrossRef]

23. Villon, S.; Mouillot, D.; Chaumont, M.; Darling, E.S.; Subsol, G.; Claverie, T.; Villéger, S. A Deep learning method for accurate and fast identification of coral reef fishes in underwater images. Ecol. Inform. 2018, 48, 238-244. [CrossRef]

24. Labao, A.B.; Naval, P.C. Cascaded deep network systems with linked ensemble components for underwater fish detection in the wild. Ecol. Inform. 2019, 52, 103-121. [CrossRef]

25. Salman, A.; Jalal, A.; Shafait, F.; Mian, A.; Shortis, M.; Seager, J.; Harvey, E. Fish species classification in unconstrained underwater environments based on deep learning. Limnol. Oceanogr. Methods 2016, 14, 570-585. [CrossRef]

26. Qiu, C.; Zhang, S.; Wang, C.; Yu, Z.; Zheng, H.; Zheng, B. Improving transfer learning and squeeze- and-excitation networks for small-scale fine-grained fish image classification. IEEE Access 2018, 6, 78503-78512. [CrossRef]

27. Ditria, E.M.; Lopez-Marcano, S.; Sievers, M.; Jinks, E.L.; Brown, C.J.; Connolly, R.M. Automating the Analysis of Fish Abundance Using Object Detection: Optimizing Animal Ecology With Deep Learning. Front. Mar. Sci. 2020, 7, 1-9. [CrossRef]

28. Alshdaifat, N.F.F.; Talib, A.Z.; Osman, M.A. Improved deep learning framework for fish segmentation in underwater videos. Ecol. Inform. 2020, 59, 101121. [CrossRef]

29. Banan, A.; Nasiri, A.; Taheri-Garavand, A. Deep learning-based appearance features extraction for automated carp species identification. Aquac. Eng. 2019, 89, 102053. [CrossRef]

30. Ju, Z.; Xue, Y. Fish species recognition using an improved AlexNet model. Optik 2020, 223, 165499. [CrossRef]

31. Yu, X.; Shen, J.; Du, J. A Machine-Learning-Based Model for Water Quality in Coastal Waters, Taking Dissolved Oxygen and Hypoxia in Chesapeake Bay as an Example. Water Resour. Res. 2020, 56, 1-19. [CrossRef] 
32. Pérez-Ortiz, M.; Fernández-Delgado, M.; Cernadas, E.; Domínguez-Petit, R.; Gutiérrez, P.A.; Hervás-Martínez, C. On the Use of Nominal and Ordinal Classifiers for the Discrimination of States of Development in Fish Oocytes. Neural Process. Lett. 2016, 44, 555-570. [CrossRef]

33. Li, K.; Sidorovskaia, N.A.; Tiemann, C.O. Model-based unsupervised clustering for distinguishing Cuvier's and Gervais' beaked whales in acoustic data. Ecol. Inform. 2020, 58, 101094. [CrossRef]

34. Raza, K.; Hong, S. Fast and Accurate Fish Detection Design with Improved YOLO-v3 Model and Transfer Learning. Int. J. Adv. Comput. Sci. Appl. 2020, 11, 7-16. [CrossRef]

35. Siddiqui, S.A.; Salman, A.; Malik, M.I.; Shafait, F.; Mian, A.; Shortis, M.R.; Harvey, E.S. Automatic fish species classification in underwater videos: Exploiting pre-trained deep neural network models to compensate for limited labelled data. ICES J. Mar. Sci. 2018, 75, 374-389. [CrossRef]

36. Jalal, A.; Salman, A.; Mian, A.; Shortis, M.; Shafait, F. Fish detection and species classification in underwater environments using deep learning with temporal information. Ecol. Inform. 2020, 57, 101088. [CrossRef]

37. Chuaysi, B.; Kiattisin, S. Fishing Vessels Behavior Identification for Combating IUU Fishing: Enable Traceability at Sea. Wirel. Pers. Commun. 2020, 115, 2971-2993. [CrossRef]

38. Kylili, K.; Hadjistassou, C.; Artusi, A. An intelligent way for discerning plastics at the shorelines and the seas. Environ. Sci. Pollut. Res. 2020, 27, 42631-42643. [CrossRef] [PubMed]

39. Cantorna, D.; Dafonte, C.; Iglesias, A.; Arcay, B. Oil spill segmentation in SAR images using convolutional neural networks. A comparative analysis with clustering and logistic regression algorithms. Appl. Soft Comput. 2019, 84, 105716. [CrossRef]

40. Al-Ruzouq, R.; Gibril, M.; Shanableh, A.; Kais, A.; Hamed, O.; Al-Mansoori, S.; Khalil, M. Sensors, Features, and Machine Learning for Oil Spill Detection and Monitoring: A Review. Remote Sens. 2020, 12, 3338. [CrossRef]

41. Song, D.; Zhen, Z.; Wang, B.; Li, X.; Gao, L.; Wang, N.; Xie, T.; Zhang, T. A Novel Marine Oil Spillage Identification Scheme Based on Convolution Neural Network Feature Extraction from Fully Polarimetric SAR Imagery. IEEE Access 2020, 8, 59801-59820. [CrossRef]

42. Liu, S.; Liu, Y.; Alabia, I.D.; Tian, Y.; Ye, Z.; Yu, H.; Li, J.; Cheng, J. Impact of Climate Change on Wintering Ground of Japanese Anchovy (Engraulis japonicus) Using Marine Geospatial Statistics. Front. Mar. Sci. 2020, 7, 1-15. [CrossRef]

43. Pais, M.P.; Henriques, S.; Batista, M.I.; Costa, M.J.; Cabral, H. Seeking functional homogeneity: A framework for definition and classification of fish assemblage types to support assessment tools on temperate reefs. Ecol. Indic. 2013, 34, 231-245. [CrossRef]

44. Marini, S.; Fanelli, E.; Sbragaglia, V.; Azzurro, E.; Fernandez, J.D.R.; Aguzzi, J. Tracking Fish Abundance by Underwater Image Recognition. Sci. Rep. 2018, 8, 1-12. [CrossRef] [PubMed]

45. Fanelli, E.; Aguzzi, J.; Marini, S.; Del Del Rio, J.; Nogueras, M.; Canese, S.; Stefanni, S.; Danovaro, R.; Conversano, F. Towards Naples Ecological REsearch for Augmented Observatories (NEREA): The NEREA-Fix Module, a Stand-Alone Platform for Long-Term Deep-Sea Ecosystem Monitoring. Sensors 2020, 20, 2911. [CrossRef]

46. Franceschini, S.; Mattei, F.; D'Andrea, L.; Di Nardi, A.; Fiorentino, F.; Garofalo, G.; Scardi, M.; Cataudella, S.; Russo, T. Rummaging through the bin: Modelling marine litter distribution using Artificial Neural Networks. Mar. Pollut. Bull. 2019, 149, 110580. [CrossRef] [PubMed]

47. Sherman, B.H. Multiple marine ecological disturbance assessments for latin american and caribbean large marine ecosystems. Environ. Dev. 2017, 22, 129-142. [CrossRef]

48. Kritzer, J.P. Influences of at-sea fishery monitoring on science, management, and fleet dynamics. Aquac. Fish. 2020, 5, 107-112. [CrossRef]

49. Sala, E.; Mayorga, J.; Costello, C.; Kroodsma, D.; Palomares, M.L.D.; Pauly, D.; Sumaila, U.R.; Zeller, D. The economics of fishing the high seas. Sci. Adv. 2018, 4, 1-14. [CrossRef] [PubMed]

50. Bartholomew, D.C.; Mangel, J.C.; Alfaro-Shigueto, J.; Pingo, S.; Jimenez, A.; Godley, B.J. Remote electronic monitoring as a potential alternative to on-board observers in small-scale fisheries. Biol. Conserv. 2018, 219, 35-45. [CrossRef]

51. Luan, J.; Zhang, C.; Xu, B.; Xue, Y.; Ren, Y. The predictive performances of random forest models with limited sample size and different species traits. Fish. Res. 2020, 227, 105534. [CrossRef]

52. Gloaguen, P.; Mahévas, S.; Rivot, E.; Woillez, M.; Guitton, J.; Vermard, Y.; Etienne, M.P. An autoregressive model to describe fishing vessel movement and activity. Environmetrics 2014, 26, 17-28. [CrossRef]

53. Verweij, M.; Van Densen, W.; Mol, A. The tower of Babel: Different perceptions and controversies on change and status of North Sea fish stocks in multi-stakeholder settings. Mar. Policy 2010, 34, 522-533. [CrossRef]

54. De Souza, E.N.; Boerder, K.; Matwin, S.; Worm, B. Improving Fishing Pattern Detection from Satellite AIS Using Data Mining and Machine Learning. PLoS ONE 2016, 11, e0158248. [CrossRef]

55. Dwivedi, Y.K.; Hughes, L.; Ismagilova, E.; Aarts, G.; Coombs, C.; Crick, T.; Duan, Y.; Dwivedi, R.; Edwards, J.; Eirug, A.; et al. Artificial Intelligence (AI): Multidisciplinary perspectives on emerging challenges, opportunities, and agenda for research, practice and policy. Int. J. Inf. Manag. 2021, 57, 101994. [CrossRef]

56. Truby, J. Governing Artificial Intelligence to benefit the UN Sustainable Development Goals. Sustain. Dev. 2020, 28, 946-959. [CrossRef]

57. Nishant, R.; Kennedy, M.; Corbett, J. Artificial intelligence for sustainability: Challenges, opportunities, and a research agenda. Int. J. Inf. Manag. 2020, 53, 102104. [CrossRef] 
58. Ozigis, M.S.; Kaduk, J.D.; Jarvis, C.H. Mapping terrestrial oil spill impact using machine learning random forest and Landsat 8 OLI imagery: A case site within the Niger Delta region of Nigeria. Environ. Sci. Pollut. Res. 2018, 26, 3621-3635. [CrossRef]

59. Stock, A.; Haupt, A.; Mach, M.; Micheli, F. Mapping ecological indicators of human impact with statistical and machine learning methods: Tests on the California coast. Ecol. Inform. 2018, 48, 37-47. [CrossRef]

60. Stahl, B.C. INNOVATION GOVERNANCE Artificial Intelligence for a Better Future An. Ecosystem Perspective on the Ethics of AI and Emerging Digital Technologies Foreword by Julian Kinderlerer; Springer: Cham, Switzerland, 2021.

61. Noble, D.F. Forces of Production: A Social History of Industrial Automation; Knopf: New York, NY, USA, 1984.

62. O'Neil, C. Weapons of Math. Destruction: How Big Data Increases Inequality and Threatens Democracy; Crown Publishers: New York, NY, USA, 2016; Volume 78, No. 3; ISBN 978-0553418811.

63. Courtland, R. Bias detectives: The researchers striving to make algorithms fair. Nature 2018, 558, 357-360. [CrossRef]

64. Beyer, H.L.; Dujardin, Y.; Watts, M.E.; Possingham, H.P. Solving conservation planning problems with integer linear programming. Ecol. Model. 2016, 328, 14-22. [CrossRef]

65. Arora, S.; Van Dyck, B.; Sharma, D.; Stirling, A. Control, care, and conviviality in the politics of technology for sustainability. Sustain. Sci. Pract. Policy 2020, 16, 247-262. [CrossRef]

66. Olsson, P.; Galaz, V.; Boonstra, W.J. Sustainability transformations: A resilience perspective. Ecol. Soc. 2014, 19. [CrossRef]

67. Hammond, M. Democratic deliberation for sustainability transformations: Between constructiveness and disruption. Sustain. Sci. Pract. Policy 2020, 16, 220-230. [CrossRef]

68. Mikalsen, K.H.; Jentoft, S. Participatory practices in fisheries across Europe: Making stakeholders more responsible. Mar. Policy 2008, 32, 169-177. [CrossRef]

69. Aanesen, M.; Armstrong, C.W.; Bloomfield, H.J.; Röckmann, C. What does stakeholder involvement mean for fisheries management? Ecol. Soc. 2014, 19. [CrossRef]

70. Kvamsdal, S.F.; Eide, A.; Ekerhovd, N.-A.; Enberg, K.; Gudmundsdottir, A.; Hoel, A.H.; Mills, K.E.; Mueter, F.J.; Ravn-Jonsen, L.; Sandal, L.K.; et al. Harvest control rules in modern fisheries management. Elementa 2016, 2016, 1-22. [CrossRef]

71. Kuhlmann, S.; Rip, A. Next generation science policy and Grand Challenges. In Handbook on Science and Public Policy; Edward Elgar: Cheltenham, UK, 2019; pp. 12-25.

72. Meuwissen, M.P.M.; Feindt, P.H.; Spiegel, A.; Termeer, C.J.A.M.; Mathijs, E.; De Mey, Y.; Finger, R.; Balmann, A.; Wauters, E.; Urquhart, J.; et al. A Framework to Assess the Resilience of Farming Systems. Agric. Syst. 2019, 176, 102656. [CrossRef] 